\title{
A Rare Case of Complete Thoracic Ectopia Cordis with Clubfeet and Hands
}

\author{
Syeda Khadija ${ }^{1}$, Sabir Butt ${ }^{2}$, Sadaf Ayesha ${ }^{3}$, Muhammad Yousaf ${ }^{4}$, Annum Majeed $^{5}$
}

\begin{abstract}
Ectopia cordis is a rare congenital condition. It is defined as the abnormal position of the heart outside the thoracic cavity, associated with defects in the parietal pericardium, diaphragm, sternum, and, in most cases, cardiac malformations. Ectopia cordis was first proposed by Abott in 1998, although cases of patients with similar defects have been reported in the past. Ectopia cordis is produced by segmental defects in the mesodermal development in the third week of intrauterine life, and/or amniotic band syndrome that causes simultaneous cerebral and thoracoabdominal malformations. The existence of ectopia cordis with severe congenital heart disease may be confirmed in the prenatal period by vaginal echocardiography at 10-12 weeks of gestation or by abdominal echocardiography at 20-22 weeks. For such defects surgical correction is the only hope of survival, although the overall success rate is very poor. In recent years, surgery has been attempted in one or two phases with variable results that depend mainly on the type of associated heart disease. A 37 years old woman with gestational age of 29.5 weeks was referred for third trimester ultrasound to detect fetal anomaly. The fetal heart was seen outside lower the chest wall which was later confirmed by elective cesarean section. The heart was not covered with a membrane (pericardium). The rest of the anterior abdominal wall was intact. The abdomen was distended due to ascites.
\end{abstract}

Keywords: Ascites, Clubfeet and hands, Ectopia cordis, Thoracoabdominal, Ultrasonography.

Donald School Journal of Ultrasound in Obstetrics and Gynecology (2019): 10.5005/jp-journals-10009-1590

\section{INTRODUCTION}

Ectopia cordis is a condition in which there is partial or complete displacement of the heart outside of the thoracic cavity. It can occur either as a solitary malformation or can be associated with other abnormalities that affect the abdomen, thorax, or both. ${ }^{1}$ It is categorized into four types based on the location of the heart: cervical, in which the heart is located higher into the area of neck (3\% of cases); thoracic, in which the heart bulges anteriorly through a sternal defect ( $60 \%$ of cases); thoracoabdominal, in which the heart is located outside of the chest ( $7 \%$ of cases); and abdominal, in which the heart is located inferiorly into the abdomen (30\% of cases). ${ }^{2}$ The etiology of ectopic cordis has not been fully elaborated; however, there are various theories about this. ${ }^{3}$ The estimated prevalence of Ectopia cordis is 5.5-7.9 per million live births and its frequency is $0.1 \%$ among all congenital heart diseases. ${ }^{4,5}$ With the help of ultrasonography, early detection of fetal anomalies is becoming more common. Ectopic cordis diagnosed by ultrasound through the first trimester scan offers options of termination at earlier gestational ages which can reduce the psychological and physical trauma on some patients. ${ }^{6}$ The prenatal sonographic evaluation of ectopia cordis is comparatively easy with two-dimensional real-time ultrasonography and it depends on the presentation of a pulsating heart outside the chest of the fetus. The prenatal diagnosis in the first trimester has been recorded; however, the diagnosis before 9 weeks of gestation has not been documented. ${ }^{7}$ The ultrasound performed within the first trimester or by the start of the second trimester allows sufficient time to elaborate associated abnormalities. However, sometimes the diagnosis through ultrasonography can be difficult especially in the minor form of ectopia cordis, in such cases, it is superior to use three-dimensional scanning to demonstrate fetal bones because of greater contrast difference as compared to contiguous organs. ${ }^{8}$ \begin{tabular}{l}
\hline \hline${ }^{1-5}$ Department of University Institute of Radiological Sciences and \\
Medical Imaging Technology, Faculty of Allied Health Sciences, \\
University of Lahore, Lahore, Punjab, Pakistan \\
Corresponding Author: Syeda Khadija, Department of University \\
Institute of Radiological Sciences and Medical Imaging Technology, \\
Faculty of Allied Health Sciences, The University of Lahore, Lahore, \\
Punjab, Pakistan, Phone: $+92-0335-1543555$, e-mail: syyedakhadija55@ \\
gmail.com, syeda.khadija@rsmi.uol.edu.pk \\
How to cite this article: Khadija S, Butt S, et al. A Rare Case of Complete \\
Thoracic Ectopia Cordis with Clubfeet and Hands. Donald School J \\
Ultrasound Obstet Gynecol 2019;13(2):80-82. \\
Source of support: Nil \\
Conflict of interest: None \\
\hline
\end{tabular}

\section{Case Presentation}

A 37 years old G5P5A0 (Gravida5, para5, abortion0) woman with a gestational age of 29.5 weeks was referred for the third trimester ultrasound scan because the fundal height was greater than dates (LMP), to detect multiple pregnancy or fetal anomaly. The antenatal ultrasound scan showed a single, live, intrauterine gestation corresponding to a gestational age of 29 weeks and 5 days, on ultrasound scan, the fetal heart was visualized outside the chest wall through a defect in the lower sternum in association with anterior diaphragmatic and ventral abdominal wall defects suggestive of thoracoabdominal variety of complete ectopia cordis. There was a breach in the normal outline of the lower sternum indicating a sternal deficiency. The fetal pericardium was absent, free fluid was present in the abdominal cavity therefor abdominal circumference $(A C)$ measurement was considered unreliable. The placenta was anterior and normal with the normal amniotic fluid. Clubfeet and hands were present. The patient

(-) The Author(s). 2019 Open Access This article is distributed under the terms of the Creative Commons Attribution 4.0International License (https://creativecommons. org/licenses/by-nc/4.0/), which permits unrestricted use, distribution, and non-commercial reproduction in any medium, provided you give appropriate credit to the original author(s) and the source, provide a link to the Creative Commons license, and indicate if changes were made. The Creative Commons Public Domain Dedication waiver (http://creativecommons.org/publicdomain/zero/1.0/) applies to the data made available in this article, unless otherwise stated. 
was explained about the poor prognosis of this condition. An informed consent was obtained after she opted for medical termination of pregnancy. The autopsy confirmed all the abovementioned ultrasound features (Figs 1 and 3).

\section{Materials and Methods}

The diagnosis of complete thoracic ectopia cordis was made by the antenatal ultrasound screening. An elective cesarean section was performed in an adjacent operating theater. The sternum was entirely deficient and the heart was completely extrathoracic oriented almost at right angles to the chest wall (Fig. 2).

\section{Discussion}

Ultrasonography is the best modality for prenatal diagnosis of ectopia cordis which is further elaborated with fetal echocardiography and fetal magnetic resonance imaging (MRI) for the assessment of intracardiac anomlies. ${ }^{9}$ Sepulveda et al. in 2013 reported that the prevalence and the diagnosis of ectopia cordis are dependent on the gestational age as some cases diagnosed in the first trimester resolved later in pregnancy. The position of heart is outside the body in early stages of development. ${ }^{2}$ Ectopia cordis results from focal abnormalities in the development of mesoderm during the third week of pregnancy with coexisting amniotic band abnormalities that yield cerebral and thoracoabdominal malformations. The types of ectopia cordis are complete in which the skin overlying the sternum and the pericardium below the sternum is absent, while in the incomplete type, one of them is present. ${ }^{10}$ Ectopia cordis can occur as an isolated malposition of the heart or associated with multiple anomalies that can be classified into intracardiac and extracardiac anomalies. The intracardiac anomalies are atrial septal defect, ventricular septal defect, diverticulum of ventricle, and tetralogy of Fallot. The extracardiac anomalies are abdominal wall defects, cranial facial malformations, cleft lip and palate, anencephaly, hydrocephaly, neural tube defects, gastrointestinal defects, pulmonary hypoplasia, genitourinary defects, and chromosol abnormalities. ${ }^{9,11}$ According to Alphonso et al., all cases of complete ectopia cordis are lethal if not treated. The goal of the surgical treatment includes (1) coverage of heart with soft tissue, (2) placement of heart in thoracic cavity, (3) correction of any cardiac defect, and (4) reconstruction of the chest wall. Due to rarity and unrelated causes responsible for nonsurvival of the neonates after surgery, no uniform surgical strategy can be advised. ${ }^{12}$
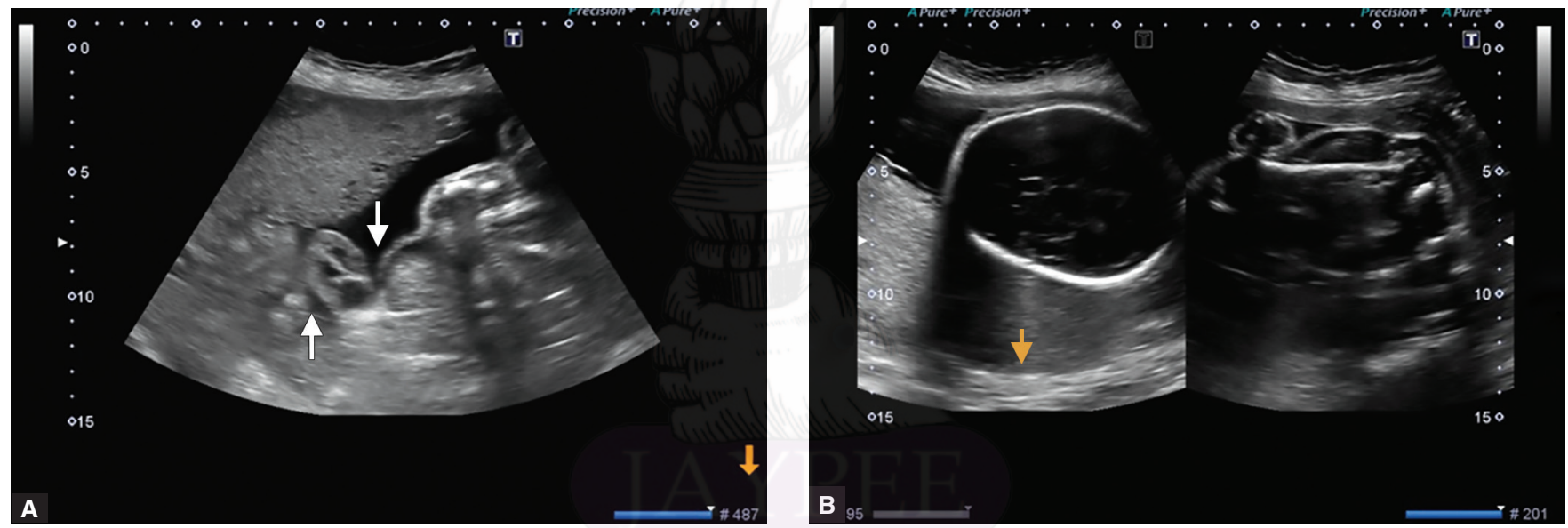

Figs 1 A and B: (A) Sonogram of fetal heart which is outside the thoracic cavity; (B) Normal biparietal diameter (BPD) femur length (FL)
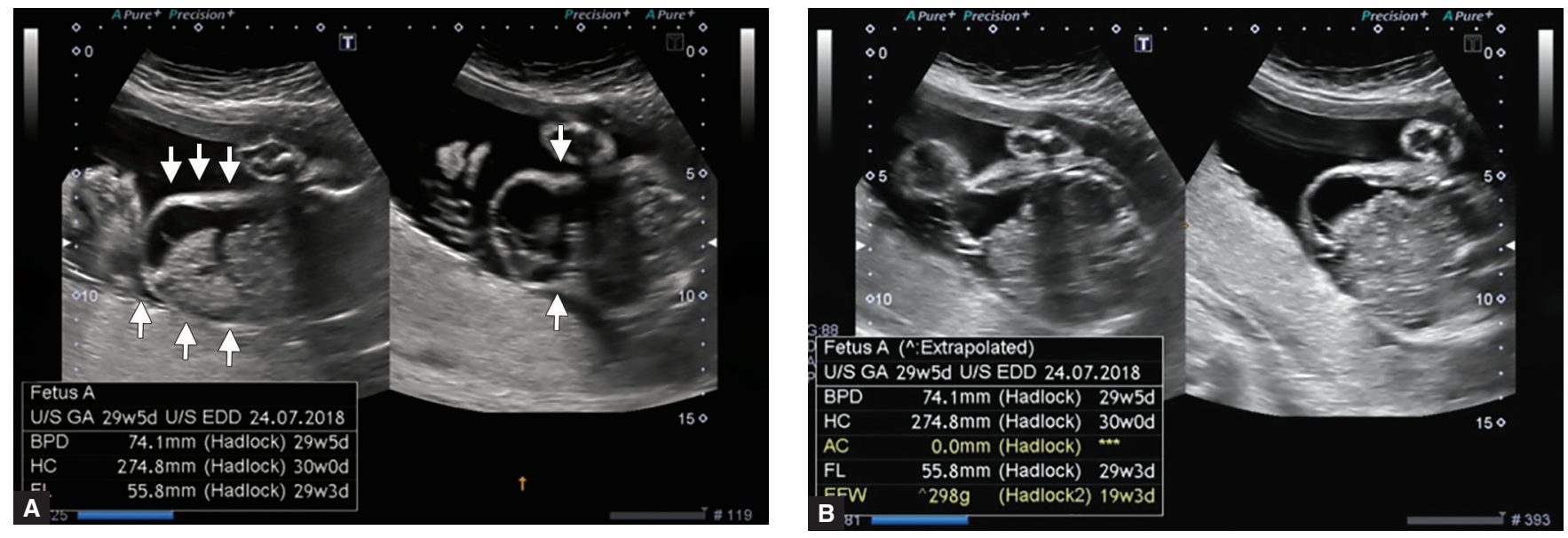

Figs 2A and B: (A) and (B) Mild abdominal ascites 


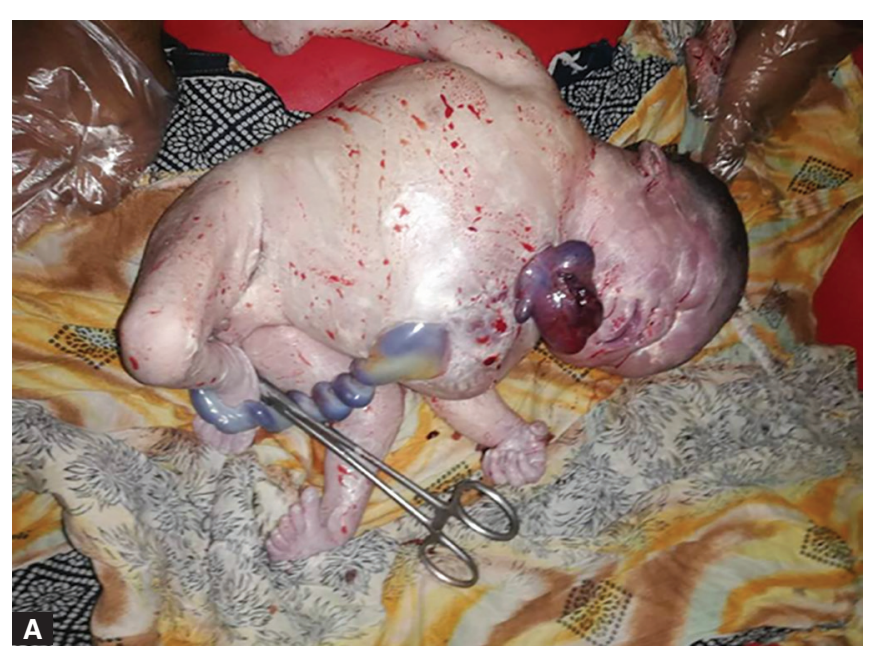

\section{References}

1. Muktan D, Singh RR, et al. Thoracic Ectopia Cordis. J Nepal Paediatr Soc 37(3):293-295. DOI: 10.3126/jnps.v37i3.18662.

2. Sepulveda W, Wong AE, et al. Ectopia Cordis in a First-Trimester Sonographic Screening Program for Aneuploidy. J Ultrasound Med 2013 May;32(5):865-871. DOI: 10.7863/jum.2013.32.5.865.

3. Escobar-Diaz MC, Sunderji $S$, et al. The fetus with ectopia cordis: experience and expectations from two centers. Pediatr Cardiol 2017 Mar 1;38(3):531-538. DOI: 10.1007/s00246-016-1545-x.

4. Shad J, Budhwani K, et al. Rare disease: thoracic ectopia cordis. BMJ Case Rep 2012;2012:bcr1120115241. DOI: 10.1136/bcr.11.2011.5241.

5. Çelik Y, Hallıŏlu O, et al. A rare case of cardiac anomaly: prenatally diagnosed ectopia cordis. Turkish Archives of Pediatrics/Türk Pediatri Arşivi 2015 Jun;50(2):129. DOI: 10.5152/tpa.2015.927.

6. Hannoun A, Usta IM, et al. First trimester sonographic diagnosis of ectopia cordis: a case report and review of the literature. J MaternFetal Neonat Med 2011 Jun 1;24(6):867-869. DOI: 10.3109/14767058. 2010.531306.

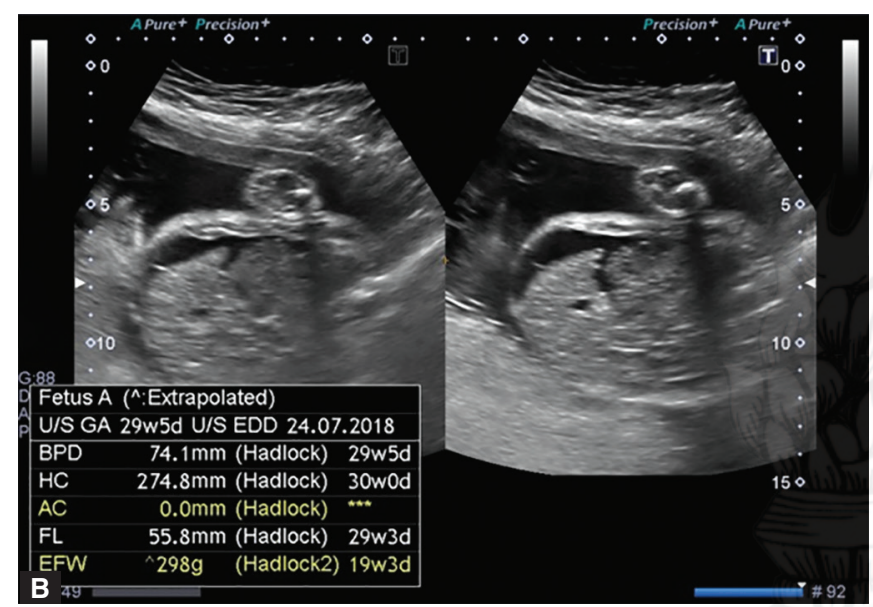

7. Sepulveda W, Andreeva $E$, et al. Sonographic diagnosis of ectopia cordis before 9 weeks of gestation. Prenatal Diagn 2014 Dec;34(12): 1231-1232. DOI: 10.1002/pd.4450.

8. Ramasauskaite D, Snieckuviene V, et al. A Rare Case Report of Thoracic Ectopia Cordis: An Obstetrician's Point of View in Multidisciplinary Approach. Case Rep Pediatr 2016;2016:1-3. DOI: 10.1155/2016/5097059.

9. Shrestha $\mathrm{R}$, Chhetri S, et al. Ectopia cordis-a rare congenital condition. Nepal J Obstet Gynaecol 2017 Jan 1;12(1):59-61. DOI: 10.3126/njog. v12i1.18984.

10. Agrawal SN, Joshi VK, et al. Ectopia cordis: a case report. Int Surg J 2018;5:739-742. DOI: 10.18203/2349-2902.isj20180386.

11. Sabeh MI, Ammar AA, et al. Prenatal diagnosis of thoracic ectopia cordis: a case report. Prenatal Diagn 2016;3(1):56-59.

12. Alphonso N, Venugopal PS, et al. Complete thoracic ectopia cordis. Eur J Cardio-Thorac Surgery 2003 Mar 1;23(3):426-428. DOI: 10.1016/ s1010-7940(02)00811-4.

Figs 3A and B: (A) Complete thoracoabdominal heart outside the chest; (B) Abdominal ascites

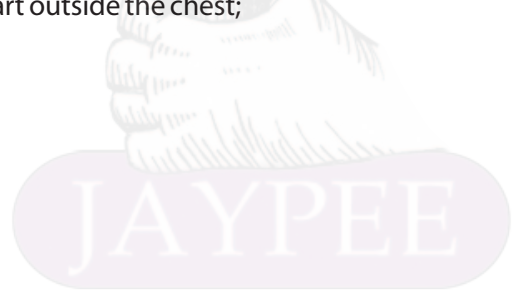

